\title{
KONDISI IKAN KARANG FAMILI CHAETODONTIDAE DI KAWASAN ZONA INTI DAN ZONA PEMANFAATAN TERBATAS TAMAN PULAU KECIL KOTA PADANG
}

\section{THE CONDITION OF REEF FISH Chaetodontidae FAMILY IN THE CORE ZONE AND THE LIMITED USE ZONE OF THE SMALL ISLAND PARK OF THE PADANG CITY}

\author{
Mohd. Yusuf Amrullah ${ }^{1 *}$ Wahyuni Rahmadani ${ }^{2}$ \\ ${ }^{1}$ Dosen, Fakultas Perikanan, Universitas Muara Bungo - Jambi \\ ${ }^{2}$ Staf Peneliti, Yayasan Minang Bahari - Padang \\ *Email: siginjai1981@gmail.com
}

\begin{abstract}
ABSTRAK
Salah satu ikan yang hidup di terumbu karang adalah ikan famili Chaetodontidae. Ikan ini merupakan ikan indikator terumbu karang. Tujuan penelitian ini adalah mendapatkan data mengenai ikan karang Famili Chaetodontidae di Taman Pulau Kecil Kota Padang di area Zona Inti dan Zona Pemanfaatan terbatas. Penelitian ini dilaksanakan di Perairan Taman Pulau Kecil Kota Padang, untuk Zona Inti (Air Dingin dan Pulau Bindalang) dan Zona Pemanfaatan Terbatas (Pulau Pasumpahan bagian Timur dan Pulau Sikuai bagian Tenggara dan bagian barat). Penelitian berlangsung dari Bulan Maret-April 2018. Metode yang digunakan dalam penelitian ini adalah Metode Underwater Visual Sensus (UVC). Pada perairan zona inti "Air Dingin" ditemukan 4 jenis ikan dari family Chaetodontidae dengan jumlah individu sebanyak 33 ekor, sedangkan pada P. Bindalang ditemukan dengan jumlah 15 ekor dengan total jumlah individu ikan karang di Zona Inti sebanyak 48 ekor (individu). Pada zona pemanfaatan terbatas ditemukan jumlah individu ikan karang family Chaetodontidaer sebanyak 27 ekor di Pulau Pasumpahan bagian Timur, perairan P. Sikuai bagian Tenggara sebanyak 18 ekor dan P. Sikuai bagian Barat sebanyak 13 ekor dengan total jumlah individu ikan karang di Zona Pemanfaatan sebanyak 58 ekor (individu).
\end{abstract}

Kata Kunci: Ikan Karang, Chaetodontidae, Taman Pulau Kecil, Kota Padang

\begin{abstract}
One of the fish that lives on coral reefs is the Chaetodontidae family. This fish is an indicator or coral reef fish. The purpose of this study is to get data about the reef fish chaetodontidae family in the core zone and the limited use zone of the small island park of the Padang City, for the core zone (Air Dingin and Bindalang Island) and the limited use zone (Pasumpahan Island the eastern part and Sikuai Island the southeastern part and the western part). The research from march - april $2018^{\text {th }}$. Method used in research with Underwater Visual Sensus (UVC). In the water core zone "Air Dingin" there were $4^{\text {th }}$ species of fish from the Chaetodontidae family with $33^{\text {rd }}$ individuals, while Bindalang island there were $15^{\text {th }}$ individual. With a total of $48^{\text {th }}$ reef fish Chaetodontidae family in the core zone. In limited utilization zone, the fish coral reef Chaetodontidae family fish as many as $27^{\text {th }}$ at Pasumpahan island the eastern part, Sikuai Island the southeastern part at many $18^{\text {th }}$ and Sikuai Island the western part at $13^{\text {rd }}$ with a total of $58^{\text {th }}$ reef fish Chaetodontidae family in the limited use zone.
\end{abstract}

Key word: coral reef fish, Chaetodontidae, the small island park of the Padang City. 


\section{PENDAHULUAN}

Ikan karang merupakan organisme yang jumlah biomassanya terbesar dan juga merupakan organisme besar yang mencolok dan dapat ditemui di dalam ekosistem terumbu karang. Kondisi fisik terumbu karang yang kompleks memberikan andil bagi keragaman dan produktivitas biologinya (Risamasu, 2003).

Melalui Surat Keputusan Gubernur No. 523.6-150-2017, Kota Padang sebagai salah satu daerah yang masuk kedalam kawasan yang memiliki Kawasan Konservasi Perairan Daerah (KKPD) menetapkan suatu kawasan pengelolaan kawasan dan konservasi yang dinamakan kawasan Taman Pulau Kecil Kota Padang yang merupakan suatu kawasan pencadangan dalam kegiatan pelestarian terhadap ekosistem laut dengan luas kawasan 2.274,96 Ha. (SK Pencadangan No.224/2011).

Pada tahun 2016 dan 2017, perairan barat sumatera tidak terkecuali perairan Kota Padang, juga mengalami fenomena alam berupa global warming (kenaikan suhu perairan) sehingga banyaknya terumbu karang yang mengalami

\section{METODE PENELITIAN}

\section{Waktu dan Tempat}

Penelitian ini dilaksanakan di Perairan Taman Pulau Kecil Kota Padang, untuk Zona Inti (Air dingin dan Pulau Bindalang) dan Zona Pemanfaatan (Pulau pemutihan dan mati serta berkembangnya bulu seribu (Achantaster planci) sebagai predator terumbu karang sehingga juga menyebabkan meningkatnya kematian karang diperairan Kota Padang. (SANARI, 2016); (2017).

Ikan Chaetodontidae merupakan salah satu organisme yang berhubungan langsung dengan terumbu karang dengan jumlah yang banyak dan merupakan kelompok ikan indikator pada ekosistem terumbu karang, selain penyebarannya luas, keberadaannya juga dipengaruhi oleh kondisi terumbu karang. Eksploitasi ekosistem terumbu karang memberi pengaruh terhadap hewan asosiasi pada ekosistem terumbu karang termasuk ikan Chaetodontidae yang merupakan penghuni terumbu karang yang memanfaatkan polip karang sebagai makanannya. (Nurjirana, 2017).

Tujuan dari penelitian ini adalah mendapatkan data mengenai ikan karang Famili Chaetodontidae di Taman Pulau Kecil Kota Padang di area Zona Inti dan Zona Pemanfaatan terbatas.

Pasumpahan Timur dan Pulau Sikuai). Penelitian berlangsung dari Bulan MaretApril 2018. Titik Koordinat lokasi penelitian dapat dilihat pada Tabel 1 sebagai berikut.

Tabel 1. Titik Koordinat Lokasi Penelitian

\begin{tabular}{|c|c|c|c|}
\hline \multirow{2}{*}{ No } & \multirow{2}{*}{ Nama } & \multicolumn{2}{|c|}{ Koordinat } \\
\hline & & Long & Lat \\
\hline 1 & Air Dingin & $100^{\circ} 22^{\prime} 23.7^{\prime \prime}$ & $01^{0} 06^{\prime} 57.4^{\prime \prime}$ \\
\hline 2 & Pulau Pasumpahan Timur & $100^{0} 22^{\prime} 09.5^{\prime \prime}$ & $01^{0} 7^{\prime} 16.6^{\prime \prime}$ \\
\hline 3 & Pulau Sikuai Tenggara & $100^{0} 21^{\prime} 13.5^{\prime \prime}$ & $01^{0} 07^{\prime} 51.0^{\prime \prime}$ \\
\hline 4 & Pulau Sikuai Barat & $100^{\circ} 21^{\prime} 01.5^{\prime \prime}$ & $01^{0} 07^{\prime} 34.2^{\prime \prime}$ \\
\hline 5 & Pulau Bindalang & $100^{\circ} 12^{\prime} 28.5^{\prime \prime}$ & $00^{0} 58^{\prime} 46.5^{\prime \prime}$ \\
\hline
\end{tabular}




\section{Metode Pengumpulan Data dan Analisa Data}

Metode yang digunakan dalam penelitian ini adalah Metode Underwater Visual Sensus (UVC) dengan modifikasi yang dikembangkan (English et al. 1994). UVC adalah metode yang cepat, akurat, efektif dan ramah lingkungan, dan dapat menghasilkan data yang relevan karena ikan karang bersifat diurnal (aktif pada siang hari). Oleh karena itu pendekatan waktu pengambilan data sensus visual yang ideal dilakukan pada rentang waktu pagi hari hingga sore hari mendekati senja (antara pukul 09:00 sampai dengan pukul 16:00). Pendekatan waktu juga memperhatikan kondisi pasang dan surut air laut, karena dapat mempengaruhi visibility perairan. Pengambilan data ikan biasanya dilakukan secara bersama setelah

\section{Analisa Data}

Keanekaragaman spesies adalah jumlah spesies ikan karang yang teridentifikasi selama penyelaman. Kelimpahan ikan yang diperoleh melalui pendataan visual sensus (English et al. 1994) dihitung dengan rumus sebagai berikut:

\section{HASIL DAN PEMBAHASAN}

Kelimpahan dan Komposisi Ikan Karang Data primer dari hasil pengamatan ikan karang yang berada pada saat penelitian dapat dibagi menjadi:

1. Family Chaetodontidae di Zona Inti Di zona inti Taman Pulau Kecil Kota Padang, dilakukan pengamatan ikan karang family Chaetodontidae pada perairan Air Dingin dan Pulau Bindalang. Pada perairan zona inti "Air Dingin" ditemukan 4 jenis ikan dari family Chaetodontidae dengan jumlah individu sebanyak 33 ekor dengan jenis ikan Heniochus pleurotaenia dengan jumlah 20 ekor dan $H$. singularis dengan jumlah 6 ekor. Sedangkan pada zona inti P. Bindalang ditemukan 6 beberapa menit dari pemasangan transek garis tersebut, di mana tiap ikan yang berada dan melintas dicatat. Pencatatan dilakukan untuk tiap jenis dan kelimpahan ikan yang dijumpai mulai dari titik nol sampai dengan transek 50 meter luas pengamatan. Pengamatan juga dilakukan pada tiap sisi kanan dan kiri dengan masing-masing sejauh 2,5 meter sehingga area pengamatan mencakup luasan $100 \mathrm{~m}^{2}$ ) (English et al. 1994). Selain itu, dapat juga diambil foto dan video bawah air untuk ikan yang sulit diidentifikasi secara langsung lalu di identifikasi menggunakan buku literatur Gerald R. Allen (Reef Fish Identification dan marine Fishes) dan Kuitter-Tonozuka (Indonesian Reef Fishes).

Keterangan;

$\mathrm{N}=$ Kelimpahan ikan (individu/ $\mathrm{m}^{2}$ )

$\mathrm{ni}=$ Jumlah individu ikan Jenis Ke-i

$\mathrm{A}=$ Luas area sensus ikan $\left(\mathrm{m}^{2}\right)$

jenis kan dari family Chaetodontidae dengan jumlah 15 ekor dimana jenis ikan yang ditemukan adalah Chaetodon trifaciatus dan Forcipiger flavissimus dengan jumlah masing-masing 4 ekor. (Tabel 2). Sedangkan grafik keanekaragaman jenis ikan family Chaetodontidae pada zona inti Taman Pulau Kecil, untuk perairan Air Dingin ditemukan jenis Heniochus pleurotaenia sebesar $61 \%$ dan $H$. singularis sebesar $18 \%$. Pada perairan P. Bindalang ditemukan jenis Forcipiger flavissimus sebesar $27 \%$, Chaetodon trifasciatus sebesar $27 \%$ dan Heniochus pleurotenia sebesar $20 \%$ (Gambar 1.) 
Tabel 2. Hasil Pengamatan Ikan Family Chaetodontidae di Zona Inti Taman Pulau Kecil Kota Padang

\begin{tabular}{|c|c|c|c|c|c|c|}
\hline \multirow[b]{2}{*}{ NO } & \multirow[b]{2}{*}{ CHAETODONTIDAE } & \multicolumn{2}{|c|}{ Zona Inti } & \multirow{2}{*}{ 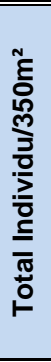 } & \multirow{2}{*}{ 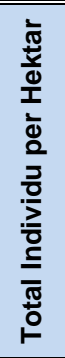 } & \multirow{2}{*}{ 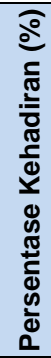 } \\
\hline & & $\begin{array}{l}\text { 응 } \\
\text { 듬 } \\
\text { 产 }\end{array}$ & 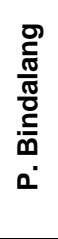 & & & \\
\hline 1 & Chaetodon triangulum & 5 & 0 & 5 & 143 & 50 \\
\hline 2 & Chaetodon falcula & 0 & 1 & 1 & 29 & 50 \\
\hline 3 & Chaetodon meyersi & 0 & 1 & 1 & 29 & 50 \\
\hline 4 & Chaetodon trifasciatus & 2 & 4 & 6 & 171 & 100 \\
\hline 5 & Forcipiger flavissimus & 0 & 4 & 4 & 114 & 50 \\
\hline 6 & Heniochus singularis & 6 & 2 & 8 & 229 & 100 \\
\hline 7 & Heniochus pleurotaenia & 20 & 3 & 23 & 657 & 100 \\
\hline \multicolumn{2}{|c|}{ Jumlah Individu (ekor) } & 33 & 15 & 48 & 1371 & \\
\hline \multicolumn{2}{|c|}{ Keanekaragaman Jenis } & 4 & 6 & 7 & 200 & \\
\hline \multicolumn{2}{|c|}{ jumlah Individu (ind/Ha) } & 943 & 429 & & 1371 & \\
\hline
\end{tabular}
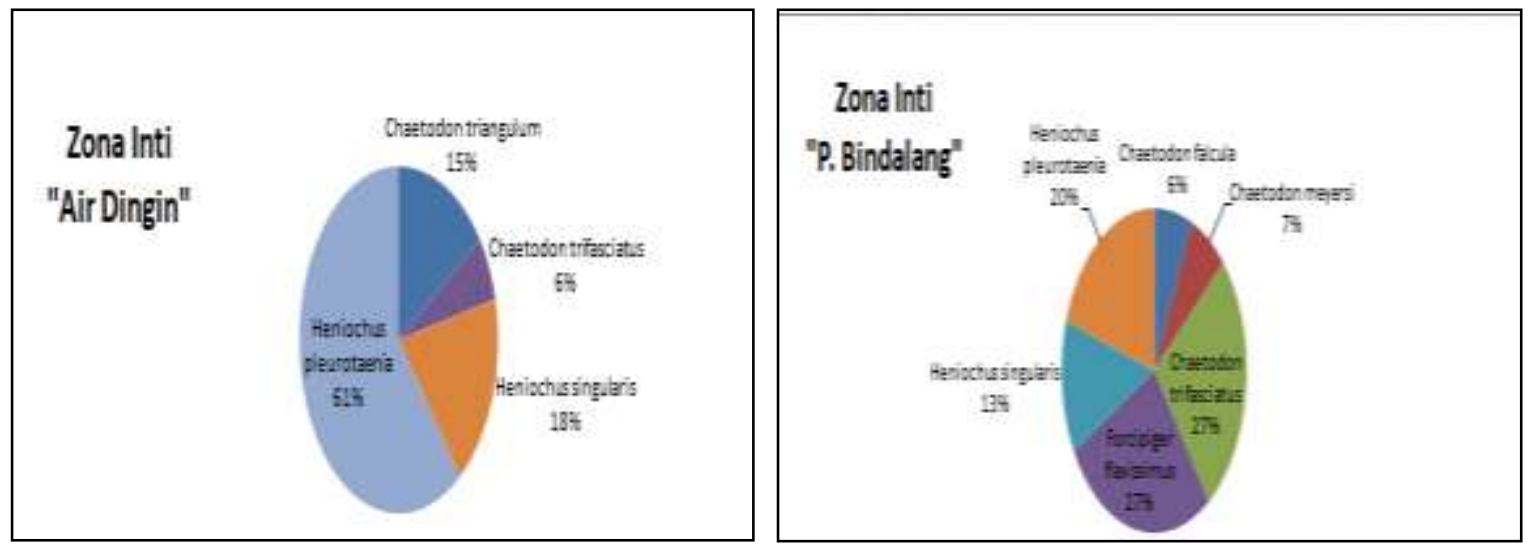

Gambar 1. Kelimpahan Ikan Family Chaetodontidae di Zona Inti Taman Pulau Kecil Kota Padang.

Dilihat dari dua lokasi perairan zona inti, perairan Air Dingin dan perairan P. Bindalang (Tabel 2 dan Gambar 1) menunjukkan, bahwa kondisi ikan karang jenis Chaetodontidae di perairan Air Dingin memiliki jumlah individu yang cukup baik dibandingkan dengan perairan di Pulau Bindalang namun untuk keanekaragaman jenis ikan Chaetodontidae di zona inti Taman Pulau Kecil Kota Padang dijumpai 7 jenis Family Chaetodontidae dimana perairan
Pulau Bindalang memiliki keanekaragaman jenis yang paling banyak dijumpai sebesar 6 jenis Family Chaetodontidae dari pada perairan air Dingin dengan jumlah 4 jenis Family Chaetodontidae.

Perbedaan ini diduga adanya pengaruh komposisi struktur dan substrat dasar perairan yang menjadi faktor pembatas keberadaan ikan Chaetodontidae, khususnya tutupan karang hidup yang menjadi makanan utama dari ikan 
Chaetodontidae sehingga dijadikan sebagai ikan indikator untuk menilai kondisi terumbu karang. Menurut Marsaoli (1998) dan Nurjirana (2017) mengatakan kelimpahan ikan pemakan karang hidup tinggi dan menurun sejalan dengan besarnya perubahan penutupan karang. Hal

2. Family Chaetodontidae di Zona Pemanfaatan Terbatas

Pada zona pemanfaatan terbatas di Taman Pulau Kecil Kota Padang merupakan suatu kawasan perairan yang dimanfaatan sebagai suatu kawasan pariwisata, baik wisata daratan maupun wisata bahari. Pada pengamatan di zona Pemanfaatan dibagi menjadi 3 lokasi yaitu Pulau Pasumpahan bagian Timur, Pulau ini disebabkan karena penutupan karang hidup yang tinggi menyediakan pakan dalam jumlah banyak sehingga ikan pemakan karang dengan mudah mendapatkan pakan untuk kebutuhan pertumbuhan dan perkembangan populasi.

Sikuai bagian Tenggara dan bagian Barat. Pada perairan Pulau Pasumpahan bagian Timur, ditemukan jumlah individu ikan karang family Chaetodontidaer sebanyak 27 ekor, perairan P. Sikuai bagian Tenggara sebanyak 18 ekor dan P. sikuai bagian Barat sebanyak 13 ekor dengan total jumlah individu ikan karang di Zona Pemanfaatan sebanyak 58 ekor (individu) (Tabel 3).

Tabel 3. Hasil Pengamatan Ikan Family Chaetodontidae di Zona Pemanfaatan Terbatas Taman Pulau Kecil Kota Padang.

\begin{tabular}{|c|c|c|c|c|c|c|c|}
\hline \multirow[b]{2}{*}{ NO } & \multirow[b]{2}{*}{ CHAETODONTIDAE } & \multicolumn{3}{|c|}{$\begin{array}{c}\text { Zona } \\
\text { Pemanfaatan }\end{array}$} & \multirow[b]{2}{*}{ 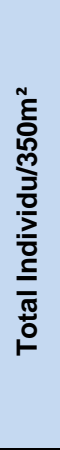 } & \multirow[b]{2}{*}{ 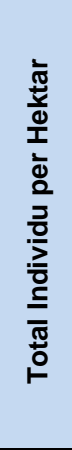 } & \multirow[b]{2}{*}{ 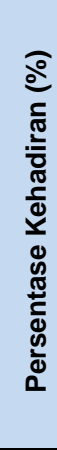 } \\
\hline & & 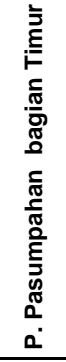 & 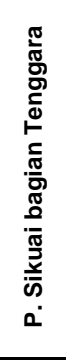 & 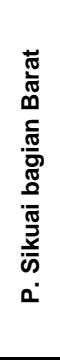 & & & \\
\hline 1 & Chaetodon triangulum & 1 & 1 & 0 & 2 & 57 & 67 \\
\hline 2 & Chaetodon citrinellus & 0 & 0 & 2 & 2 & 57 & 33 \\
\hline 3 & Chaetodon Kleinii & 0 & 0 & 1 & 1 & 29 & 33 \\
\hline 4 & Chaetodon Collare & 2 & 0 & 0 & 2 & 57 & 33 \\
\hline 5 & Chaetodon lineolatus & 3 & 0 & 0 & 3 & 86 & 33 \\
\hline 6 & Chaetodon lunula & 0 & 1 & 0 & 1 & 29 & 33 \\
\hline 7 & Chaetodon rafflesii & 0 & 2 & 0 & 2 & 57 & 33 \\
\hline 8 & Chaetodon vagabundus & 0 & 0 & 3 & 3 & 86 & 33 \\
\hline 9 & Chaetodon trifasciatus & 3 & 1 & 0 & 4 & 114 & 67 \\
\hline 10 & Forcipiger flavissimus & 0 & 0 & 4 & 4 & 114 & 33 \\
\hline 11 & Heniochus pleurotaenia & 7 & 13 & 3 & 23 & 657 & 100 \\
\hline \multirow[t]{4}{*}{12} & Heniochus acuminatus & 11 & 0 & 0 & 11 & 314 & 33 \\
\hline & Jumlah Individu (ekor) & 27 & 18 & 13 & 58 & 1657 & \\
\hline & Keanekaragaman Jenis & 6 & 5 & 5 & 12 & 343 & \\
\hline & jumlah Individu (ind/Ha) & 771 & 514 & 371 & & 1286 & \\
\hline
\end{tabular}


Untuk keanekaragaman jenis ikan Family Chaetodontidae di Zona Pemanfaatan Terbatas Taman Pulau Kecil Kota Padang, pada Pulau Pasumpahan bagian Timur didapatkan 6 jenis ikan family Chaetodontidae dimana Heniochus acuminatus sebesar $41 \%$ dan $H$. pleurotaenia sebesar 26\%. Untuk Pulau Sikuai bagian Tenggara didapatkan 5 jenis ikan family Chaetodontidae dimana Heniochus pleurotenia sebesar $72 \%$ dan Chaetodon rafflesii sebesar $11 \%$, sedangkan di P. Sikuai bagian Barat didapatkan 5 jenis ikan family Chaetodontidae dimana forcipiger flavissimus sebesar $31 \%$ dan Heniochus pleurotaenia dan Chaetodontidae masingmasing sebesar 23\%. (Gambar 2).

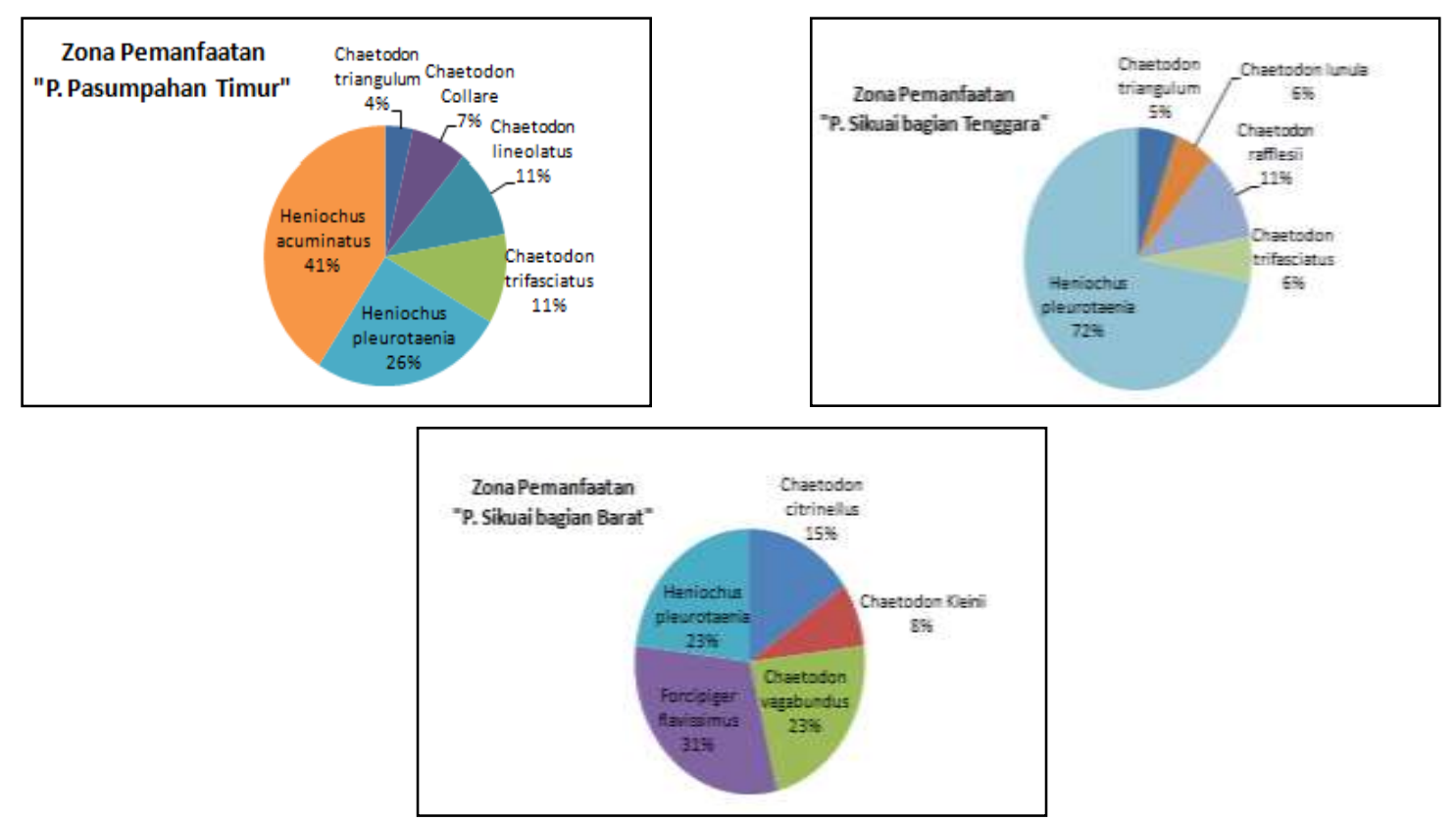

Gambar 2. Kelimpahan Ikan Family Chaetodontidae di Zona Pemanfaatan Terbatas Taman Pulau Kecil Kota Padang.

Ketiga lokasi pengamatan di Zona Pemanfaatan terbatas, dijumpai bahwa jenis Heniocus pleurotaenia yang paling sering dijumpai di tiap lokasi pengamatan dengan total individu sebesar 23 individual, dimana Perairan Pulau Pasumpahan bagian Timur untuk keanekaragaman jenis adalah yang paling

Dari dua kawasan yang terdapat di Taman Pulau Kecil Kota Padang, yaitu zona inti dan zona pemanfaatan terbatas didapatkan bahwa keanekaragaman jenis ikan karang family Chaetodontidae sangat rendah, hal ini diduga kurangnya tutupan karang hidup.

Keanekaragaman spesies dan kelimpahan ikan akan meningkat sejalan dengan meningkatnya tutupan karang hidup. Meningkatnya persentase tutupan karang mati menyebabkan penurunan yang tinggi sebesar 6 jenis. Menurut Al Tanto et al (2017), pada Pulau Pasumpahan ditemukan 37 jumlah individu dengan keanekaragaman jenis sebanyak 14 jenis. Amrullah (2018), mengatakan bahwa ikan karang family Chaetodontidae (kupukupu) di perairan Pulau Pasumpahan dijumpai sebanyak 14 spesies.

nyata dalam jumlah spesies ikan maupun individu-individu ikan yang berasosiasi dengan terumbu karang.

Rendahnya jumlah spesies yang dijumpai terutama disebabkan oleh rendahnya kecerahan akibat tingginya sedimentasi dan banyaknya debris yang menutup biota karang, serta adanya peningkatan suhu yang cukup ekstrem yang menyebabkan kematian karang (bleaching effect) (Suharti, et.al, 2018). Banyak penelitian menemukan hubungan 
positif antara jumlah spesies ikan KepeKepe ini dengan kesehatan terumbu karang (Suharsono et al. 1998; Yusuf \& Ali 2001; Mujianto et al. 2011). Selain itu penelitian yang dilakukan di perairan Barat Sumatera pada tahun 2015, menunjukkan adanya kenaikan suhu permukaan laut (SST) yang

\section{KESIMPULAN}

Rendahnya keragaman ikan coralivora sebagai indikator kesehatan terumbu karang di Taman Pulau Kecil Kota Padang menunjukkan kondisi terumbu karang secara umum berada dalam kondisi kurang baik. Fenomena ini disebabkan karena pernah adanya pemutihan karang (coral bleaching), dan banyak debris menutup biota karang. Pada hasil penelitian, jumlah individu terbanyak yang dijumpai berada di perairan zona inti "Air Dingin" dengan jumlah 33 ekor individu dan yang terendah pada zona pemanfaatan terbatas "Pulau Sikuai bagian Barat" dengan jumlah individu 13 ekor. Adapun jenis ikan karang family Chaetodontidae yang selalu hadir disetiap lokasi penelitian di Taman Pulau Kecil Kota Padang adalah jenis

\section{UCAPAN TERIMA KASIH}

Terima kasih kami ucapkan kepada Kepala Dinas Kelautan dan Perikanan Provinsi Sumatera Barat atas dukungannya dalam pelaksanaan kegiatan ini. Terima kasih

\section{DAFTAR PUSTAKA}

Allen, G.R. Indo-Pasific Coral Reef Fishes as Indicator of Conservation Hotspot. In International Coral Reef Symposium, Bali, Indonesia. 9th., ed. Vol II: Denpasar

Eakin CM, G Liu, AM Gomez, JL De La Cour, SF Heron, WJ Skirving, EF Geiger, KV Tirak \& AE Strong. (2016). Global coral bleaching 20142017, Status and an appeal for observations. Reef Encounter, 43 31(1): 20-26.

English, et.al. (1994). Survey Manual for Tropical Marine Resources. berpengaruh pada fenomena pemutihan karang (Wisha et al. 2016). Fenomena pemutihan karang/coral bleaching diperkuat oleh penelitian yang dilakukan oleh Eakin et al. (2016) yang menjelaskan adanya global coral bleaching.

Heniochus pleurotaenia dengan persentase kehadiran $100 \%$ yang mana jenis ini adalah pemakan zooplankton. Pada perairan zona inti "Air Dingin" ditemukan 4 jenis ikan dari family Chaetodontidae dengan jumlah individu sebanyak 33 ekor, sedangkan pada P. Bindalang ditemukan dengan jumlah 15 ekor dengan total jumlah individu ikan karang di Zona Inti sebanyak 48 ekor (individu). Pada zona pemanfaatan terbatas ditemukan jumlah individu ikan karang family Chaetodontidaer sebanyak 27 ekor di Pulau Pasumpahan bagian Timur, perairan P. Sikuai bagian Tenggara sebanyak 18 ekor dan P. Sikuai bagian Barat sebanyak 13 ekor dengan total jumlah individu ikan karang di Zona Pemanfaatan sebanyak 58 ekor (individu).

juga kepada pimpinan CV. SANARI, Wahyuni Rahmadani membantu dalam pengambilan data serta semua pihak yang membantu terlaksananya seluruh kegiatan penelitian sampai selesai.

Australian Institute of Marine Science, Townsville.

Kuiter, R.H. (1992). Tropical Reefs Fishes of the Westren Pasific Indonesi Adjacent Water. Gramedia Jakarta. $314 \mathrm{p}$

Marsaoli, MK. (1998). Hubungan Persentase Penutupan Karang Hidup dengan Densitas Beberapa Jenis Ikan Karang di Perairan Kepulauan Karimunjawa, Jepara. Tesis. Institut Pertanian Bogor. Bogor

Amrullah. M. Y, Hendri Putrananda (2018). Kelimpahan Ikan Karang Pada Terumbu Karang Buatan Di 
Lokasi Yang Berbeda Perairan Kota Padang. UNES Journal of Scientech Research Volume 3, Issue 1, Juni 2018 P-ISSN 2528-5556 E-ISSN 2528-6226

Mujiyanto Y, Sugianti \& ST Hartati. (2011). Hubungan kelimpahan ikan famili Chaetodontidae dengan kondisi terumbu karang di perairan Jemeluk Bali. Pros. Seminar Nasional: Strategi pembangunan perikanan dan kelautan berwawasan lingkungan. Fak. Perikanan Univ. Pancasakti. Tegal: 1-14.

Nurjirana, Andi Iqbal Burhanuddin. (2017). Kelimpahan Dan Keragaman Jenis Ikan Famili Chaetodontidae Berdasarkan Kondisi Tutupan Karang Hidup Di Kepulauan Spermonde Sulawesi Selatan. Spermone (2017)2(3):34-42 ISSN: 2460-0156

Risamasu. L. Fonny J. (2003). Makalah Individu "Studi Tentang Kelimpahan Ikan Karang Pada Terumbu Karang Buatan (Artificial Reefs) Di Perairan Hansisi, Semau, Kupang. Pengantar Falsafah Sains (PPS702) Program Pascasarjana/S3, IPB. November 2003.

SANARI. (2016). Laporan Akhir Rehabilitasi Ekosistem Pesisir dan Laut "Terumbu Karang Buatan Di Kawasan Konservasi Kota Padang". 35 Hal

SANARI. (2017). Laporan Akhir Rehabilitasi Ekosistem Pesisir dan Laut "Terumbu Karang Buatan Di Kawasan Konservasi Kota Padang". $38 \mathrm{Hal}$

Suharti. SR, Isa Nagib Edrus. (2018). Kondisi Ikan Karang di Perairan Tapanuli Tengah. Oseanologi dan Limnologi di Indonesia 2018 3(2): 105-121 Online ISSN: 2477-328X

Suharsono, Giyanto, Yahmantoro \& JA Munkajee. (1998). Changes of Distribution and Abundance of Reef Fish in Jakarta Bay and Seribu Islands. In: Subagjo Soemodihardjo (ed). Proceedings Coral Reef Evaluation Workshop Pulau Seribu, Jakarta, Indonesia. Unesco. Jakarta Office dan LIPI.

Try Al Tanto, Aprizon Putra, Fredinan Yulianda . Kesesuaian Ekowisata di Pulau Pasumpahan, Kota Padang Majalah Ilmiah Globë Volume 19 No.2 Oktober 2017: 135-146

Wisha UJ, TAl Tanto \& Ilham. (2016). Spatial distribution of sea surface temperature in west Sumatera seawaters associated with Indian Ocean Dipole (IOD) event in transitional seasons (AugustOctober) case study: Pasumpahan and Sibonta Island waters (Distribusi Spasial Suhu Permukaan Laut di Perairan Barat Sumatera Dikaitkan dengan Kejadian Indian Ocean Dipole (IOD) pada Musim Peralihan (Agustus-Oktober) Studi Kasus: Perairan Pulau Pasumpahan dan Sibonta). Jurnal Ilmiah Geomatika, 22(1): 21-28

Yusuf Y \& AB Ali. (2001). Butterflyfish (Chaetodontidae) of Pulau Payar Marine Park. Proceedings of National Symposium on Pulau Payar Marine Park. 173 hal 